\title{
La estrategia argumentativa de Joaquín Lavín y la construcción de un nuevo ethos discursivo en la política chilena
}

\author{
Argumentation Strategies of Joaquín Lavín and the \\ Construction of a New Discoursive Ethos in Chilean \\ Politics
}

\section{Juan Pablo Sáez}

Universidad de Paris II

saezjuanpablo@yahoo.fr

\begin{abstract}
Resumen
El discurso político de Joaquín Lavín, militante de la Unión Demócrata Independiente y candidato de la derecha en la campaña presidencia de 1999, se caracteriza por la extrema simplificación de su contenido y por la construcción de un relato apoyado en informaciones implícitas. En este relato, donde la realidad es encuadrada y revestida de objetividad, la imagen de Pinochet sometido a escarnio público tras su arresto en Inglaterra, es separada de la herencia autoritaria de su régimen y los partidos políticos son criticados permanentemente.
\end{abstract}

Palabras claves: discurso político, argumentación, doxa, ethos discursivo.

\begin{abstract}
During the 1999 Chilean Presidential Election, the political discourse of Joaquin Lavin, right-wing candidate and UDI party activist, was characterized by an extreme simplification of content and the construction of a narrative using information implicitly. This discourse separates the image of a Pinochet submissive to public judgment from the authoritarian legacy of his regimen and, among other things, was characterized by the permanent criticism of the political parties.
\end{abstract}

Keywords: political discourse, argumentation, doxa, ethos discursive.

\section{Introducción}


Hace 18 años, cuando finalizó el régimen de Pinochet, los partidos de la Concertación por la democracia (centro izquierda), de la Alianza por Chile (centro derecha) y de la izquierda extraparlamentaria adoptaron un discurso político cuyo objetivo era contar, explicar y justificar la visión de cada uno de ellos sobre la transición política. Sostenido por una estructura legal y constitucional, el período post-dictadura cohabita con una serie de "discursos transicionales", constituidos a su vez por relatos y estrategias argumentativas que los políticos y sus partidos utilizan para atraer al electorado. Estos "discursos transicionales" -llamados así pues sus argumentaciones defienden o atacan la obra de la dictadura militar- se oponen los unos a los otros según el partido o coalición. Así, la derecha defiende en su conjunto la herencia de la dictadura, mientras que la Concertación la ataca, aunque sin poner en duda el modelo económico impuesto por el régimen militar. El partido comunista, y en general los candidatos extraparlamentarios, atacan el modelo económico y la herencia legal y constitucional del régimen, pero sobretodo las violaciones a los derechos humanos que sirvieron a imponer dicho modelo.

Esta lucha entre los partidos por imponer sus propios discursos transicionales, alcanza su punto álgido durante la campaña presidencial de 1999 que opone seis candidatos. Dos de los cuales concentran el favor de los electores: el socialista y fundador del Partido por la Democracia (PPD), Ricardo Lagos, representante de la Concertación, y Joaquín Lavín, militante de la Unión Demócrata Independiente (UDI) y representante de la Alianza por Chile. La confluencia inesperada de dos hechos históricos como la detención de Pinochet en Inglaterra y la réplica del escenario electoral de 1970, provoca una crisis de consenso entre civiles y militares y obliga a los candidatos presidenciales a tomar una posición más clara respecto de la dictadura militar. Podría afirmarse que este momento es clave en el discurso político de la derecha chilena pues la obliga a aceptar públicamente, a través de su candidato Joaquín Lavín, la irracionalidad coercitiva del régimen militar (Hunneus, 2000), aunque identificada en la persona de Pinochet y disociada de los civiles que trabajaron para él. Asimismo, podría señalarse que el reconocimiento de esta irracionalidad coercitiva nace como una estrategia de marketing político que se transforma, al final de la contienda electoral, en una posición definitiva de la Alianza por Chile.

Esta disociación entre irracionalidad coercitiva y racionalidad económica es funcional al candidato de la derecha quien debe destruir lo que Amossy llama "ethos pre-discursivo" (2006, p. 80), es decir la imagen que el electorado tiene de él antes de que se lance en la carrera a la presidencia, y construir uno nuevo, una nueva imagen de sí mismo que haga más aceptable su colaboración con el régimen militar.

Este trabajo investigará la estrategia argumentativa de Lavín, de modo tal que se pueda analizar el modo en que operan estos argumentos en la preservación de la herencia político institucional del régimen militar y en el alejamiento del candidato de la derecha respecto de Pinochet. Un análisis argumentativo del discurso político aplicado a cuatro 
alocuciones que Lavín pronunció entre mayo y noviembre de 1999 nos indica que, en la construcción de este nuevo ethos discursivo, intervienen una serie de argumentos que pueden ser agrupados en cuatro familias argumentativas, según una clasificación de Philippe Breton: "el cadrage, la comunidad, la autoridad y la analogía" (2006, p. 54). El cadrage y la comunidad se apoyan en los elementos dóxicos diseminados en el interdiscurso social, es decir, en la opinión común imperante en un momento dado de la historia (Amossy, 2006). Esto lleva al candidato de la derecha a reemplazar en muchas ocasiones sus propias creencias por aquellas de la opinión pública. Las otras dos familias argumentativas buscan la simplificación extrema del discurso electoral al acudir a la autoridad de personalidades externas a la contienda presidencial y al recurrir a ejemplos o situaciones ajenas al juego presidencial, con el fin de explicar algo complejo.

A diferencia del discurso del candidato socialista, cuyo contenido histórico y político parecía ser mucho más espeso, el discurso de Lavín, caracterizado por esta simplificación extrema, fue subvalorado y su influencia sobre futuras campañas electorales fue juzgada como incierta. Sin embargo, podría afirmarse que el éxito de los candidatos a alcalde de la UDI durante las elecciones inmediatamente posteriores a la contienda presidencial de 1999, así como la campaña "ciudadana" de la candidata Bachelet (alejada de los partidos), obedecen a un nuevo tipo de discurso político inaugurado por Lavín. Un discurso electoralmente eficaz y cuya tendencia se inscribe en el proceso de modernización de Chile, caracterizado por "una nueva sociabilidad marcada por el temor al conflicto, el desencanto utópico, la sospecha por lo diferente y la preocupación por la seguridad" (Ossa, 2006, p. 4).

El análisis argumentativo del discurso tiene por objetivo describir, de la manera lo más precisa posible, el funcionamiento discursivo y estudiar las modalidades según las cuales el discurso busca la construcción de un consenso, la polémica contra un adversario o el impacto en un cierto momento de la comunicación. El análisis argumentativo es crítico cuando él expone los elementos dóxicos que la argumentación presenta regularmente como si pertenecieran sólo a ella, aunque su vocación no es relacionar estos elementos con una ideología que podamos condenar (Amossy, 2006).

La metodología aplicada en el análisis del discurso político de Lavín es similar a la utilizada por Breton (1999) en su estudio "La preferencia manipuladora del presidente del Frente Nacional”. Primero, se eligieron cuatro discursos que Lavín pronunció en 1999 en momentos distintos aunque significativos de su campaña. Luego, estas alocuciones se analizaron y se descubrieron los argumentos allí utilizados por el candidato para, finalmente, agruparlos en cuatro familias-tipo, según la clasificación de Breton mencionada anteriormente.

El primer discurso, del 10 de mayo, es pronunciado en Santiago ante los dirigentes de la Confederación de la Producción y del Comercio (CPC), en momentos en que Lavín aún 
no es ungido como candidato único de la derecha. El segundo discurso es del 6 de junio y es pronunciado ante los militantes de la UDI y RN, seis días después de la nominación de Ricardo Lagos como candidato único de la centro-izquierda y dos días antes de la dimisión de Lavín al puesto de alcalde de Las Condes. La tercera alocución estudiada es del 5 de octubre y fue pronunciada en Calama, en el inicio de la tercera etapa de la campaña presidencial de Lavín. En ese momento el candidato de la derecha goza de gran popularidad y los sondeos de opinión anuncian la resolución de la elección en segunda vuelta. El cuarto y último discurso es del 4 de noviembre y es pronunciado nuevamente ante los dirigentes de la CPC. Esta alocución tiene lugar poco después del único debate entre Lavín y Lagos y un mes antes de la primera vuelta presidencial.

\section{Las nociones de argumentación y de ethos prediscursivo}

La argumentación "es una operación que se apoya sobre un enunciado aceptado por el auditorio para alcanzar otro menos aceptado: la conclusión. Es decir, la acción de argumentar significa dirigir a un interlocutor un argumento, una buena razón, con el fin de que él admita una conclusión e incitarlo a adoptar los comportamientos adecuados" (Plantin, 1996, p. 24). No hay argumentación posible sin un acuerdo previo del auditorio, el cual pasa por la identificación de un punto de apoyo, de un tema aceptado por el auditorio antes que la estrategia argumentativa se ponga en marcha (Breton, 2006).

La argumentación puede también ser definida como el conjunto de técnicas que sirven a la legitimación de creencias y de comportamientos. Ella busca influenciar, transformar o reforzar las creencias o comportamientos de uno o más auditorios objetivos (Plantin, 1996).

Perelman (1997) define la argumentación diferenciándola de la demostración. Mientras que en una demostración la conclusión es deducida a partir de un conjunto de normas y de premisas, los argumentos que se presentan a favor de una tesis pueden ser más o menos fuertes que aquellos que se presentan a favor de una tesis opuesta. El auditorio va a adherir a una u otra tesis en función de una apreciación de los argumentos presentados a favor o en contra y del valor de la solución que ellos ofrecen a los problemas en discusión.

Uno de los elementos de la argumentación que contribuyen poderosamente a asegurar la credibilidad y autoridad del orador es su propia imagen o ethos. Maingueneau considera que el ethos está relacionado con el ejercicio de la palabra, con el rol que le corresponde en el discurso, y no con el individuo real, independientemente de su prestación oratoria (Amossy, 2006). Desde este punto de vista, el ethos debería su existencia al acto de enunciación y no a la historia personal del locutor. Esto significaría, 
por ejemplo, que el ethos de Joaquín Lavín está siendo creado y recreado de manera permanente cada vez que él dice un discurso, interviene en un debate o es interrogado por un periodista.

Amossy (2006), en cambio, considera que existen dos tipos de ethos: uno prediscursivo, que corresponde a la imagen que el auditorio se forma del locutor antes de que éste haga uso de la palabra, y otro discursivo u oratorio, que corresponde a la imagen que el locutor proyecta de sí mismo en su discurso, replanteando los datos pre-discursivos. Charaudeau (2005) estima que estos dos tipos de ethos no se autoexcluyen, sino que están mezclados al momento de la enunciación. El ethos es, en este sentido, un cruce de miradas: la mirada del otro sobre aquel que habla y la mirada de aquel que habla sobre la manera en que el otro lo ve. Este otro, para construir la imagen del sujeto que habla, se apoya en los datos preexistentes al discurso -lo que él sabe del locutor- así como en aquellos datos aportados por el acto del lenguaje mismo.

Cuando Lavín comienza su campaña de pre-candidato, él sabe que ciertas características de su ethos pre-discursivo -como por ejemplo su cercanía con la dictadura militar y con su líder, el general Augusto Pinochet- deberán cambiar si desea captar la atención de una parte del electorado fiel a la centro izquierda. Lavín, cuya carrera política comienza justamente en el seno del régimen militar cuando él tiene tan sólo 22 años de edad, construye un discurso político que modela su historia personal, escondiendo sus compromisos con el gobierno de Pinochet. Dos elementos recuerdan este pasado de Lavín: por una parte, su trabajo en la Oficina de Planificación Nacional (Odeplán), entre 1975 y 1977, y por otra parte su militancia, desde 1988, en la UDI, partido creado durante la dictadura para defender su herencia política y económica. Estos dos elementos están íntimamente ligados a otras experiencias siempre circunscritas a su compromiso con la dictadura, como, por ejemplo, sus estudios de postgrado en economía en la Universidad de Chicago, financiados por el gobierno a través de una beca otorgada por Odeplán en 1977, y su trabajo, entre 1980 y 1988, como director de la sección de economía del diario El Mercurio, uno de los medios más conservadores del país y más comprometidos con el régimen militar.

\section{La dramaturgia política de Lavín}

Un análisis de discurso, cualquiera sea éste, "debe tomar en cuenta las condiciones históricas en las cuales el enunciado estudiado es producido" (Sarfati, 2005, p. 16). Su objetivo es estudiar un conjunto de textos a la luz de la época en que fueron producidos y descubrir el "triángulo de la dramaturgia política" (Charaudeau, 2005, p. 70) que lo sustenta. En efecto, todo discurso político que busque atraer al público a un proyecto o a 
una acción determinada, o bien a disuadirlo de seguir un proyecto adverso, insiste muy particularmente en los elementos siguientes: "a) el desorden social del cual es víctima el ciudadano, b) la fuente del mal que se encarna en un adversario y c) la solución salvadora, encarnada por el político que construye el discurso" (Charaudeau, 2005, p. 70).

Durante la campaña presidencial de 1999 tres condiciones históricas influencian de manera importante la estrategia discursiva de Lavín: primero, la crisis económica, derivada de la crisis asiática de 1997, segundo, la insatisfacción de la opinión pública frente a los actores políticos, y tercero, la omnipresencia del general Pinochet en la escena política local. El candidato de la derecha se apoya entonces en las consecuencias de la crisis económica en la población, en la insatisfacción respecto de la política y en la situación judicial de Pinochet (detenido en octubre de 1998) para construir un discurso de desorden social, del cual el Estado y las organizaciones políticas son acusadas de ser las culpables. Frente a estas tres condiciones históricas, el candidato de la Alianza por Chile se erige en solución salvadora.

Para Lavín, la causa principal de la crisis económica es la proximidad entre los actores del Estado (el Presidente de la República y los miembros de la administración pública) y las organizaciones políticas, especialmente los partidos. En el discurso pronunciado el 10 de mayo de 1999, el candidato de la derecha dice:

La manera de resolver los problemas de Chile es, antes que nada cambiando la forma y el estilo de gobernar ( ... ¿ ¿Por qué el desprestigio en que ha caído la función pública? ( ...) La razón es simple: lo que está fracasado es una forma de gobierno, que yo llamaría "político tradicional", que está cada vez más alejada del verdadero espíritu de servicio público. (1999, p.4)

A través de un argumento de disociación, Lavín separa los actores del Estado de las organizaciones políticas en términos de asepsia política: el primer grupo debería estar alejado de la discusión y negociación política, dejándola bajo el dominio del segundo grupo. Las organizaciones políticas son vistas entonces como un ruido en el camino de Chile hacia el pleno desarrollo económico. El candidato de la derecha replica así el discurso histórico de la UDI en contra de las organizaciones políticas y los partidos en particular, a través de las ideas de su fundador, el abogado Jaime Guzmán (Hunneus, 2001). 


\section{El alejamiento respecto de Pinochet}

Para conquistar al electorado, el candidato de la derecha debe luchar contra su propio ethos político, fuertemente identificado con el régimen de Pinochet, y construir una nueva imagen de sí mismo, más próxima al tecnócrata y al "político apolítico". El primer objetivo de la estrategia argumentativa de Lavín es entonces desmarcar al candidato de la figura tutelar de Pinochet, omnipresente en la agenda política del país durante toda la campaña presidencial.

Tras una difícil salida de la comandancia en jefe del Ejército, Pinochet asume como senador vitalicio de la República en marzo de 1998, cuando la carrera de Lavín hacia la candidatura única de la derecha ya está lanzada. Desde el senado, el ex dictador juega un rol importante en el proceso de designación del candidato único de la Alianza por Chile. Las declaraciones de este último sobre la positiva disminución del protagonismo del ex general en la agenda política (González Camus, 2005) molestan profundamente al senador vitalicio, quien utiliza la influencia que le resta para impedir que Lavín se transforme en candidato único. Exceptuando la defensa inicial que hace de Pinochet al inicio de su arresto en Londres, el conjunto de la campaña presidencial de Lavín (tomando en cuenta el período anterior a su designación como candidato único) se aboca a borrar todo atisbo de cercanía con el ex dictador, minimizando de manera importante su pasado de colaborador del régimen militar.

Este proceso se inicia después del triunfo de la UDI en las elecciones legislativas de diciembre de 1997 y se desarrolla con fuerza hasta la detención de Pinochet en Inglaterra, en octubre de 1998. Obligado por su partido y por el temor a perder el apoyo de la extrema derecha, el candidato decide acercarse nuevamente al ex dictador, paréntesis que dura sólo un mes. En diciembre de ese año Lavín vuelve a su discurso original -tecnócrata e independiente-, que se consolida en mayo de 1999, fecha de partida de este estudio.

Dos aspectos predominan en la estrategia argumentativa tendiente a afirmar esta posición frente a Pinochet. El primero de ellos es la extrema simplicidad del mensaje de Lavín, condición esencial del discurso político que debe ser considerada en su perspectiva persuasiva. Maingueneau y Charaudeau (2002) señalan que la simplicidad del discurso político no dice relación con el desarrollo de un razonamiento lógico con objetivos explicativos o demostrativos, que apuntan a dilucidar una verdad, sino más bien a mostrar la fuerza de la razón esgrimida. Es decir, el político que argumenta propone un razonamiento causal simple, apoyándose en creencias fuertes que, se supone, son por todos compartidas y reforzadas a través de argumentos destinados a producir un efecto de prueba.

Un segundo aspecto importante es la utilización reiterada del re-encuadre de lo real, es decir, la amplificación de ciertos aspectos de la realidad y la minoración de otros que 
podrían tener un efecto contrario al objetivo deseado por el candidato. Este re-encuadre de lo real se funda sobre la doxa predominante en la época en que el mensaje fue emitido. La doxa "corresponde al sentido común, al conjunto de representaciones socialmente predominantes, formuladas en un lenguaje corriente, y cuya verdad es incierta" (Maingueneau y Charaudeau, 2002, p. 197). Dos elementos de la doxa son predominantes en el discurso político de Lavín: la idealización del presente y la sacralización del consenso.

En los discursos del 10 de mayo y 4 de noviembre -los únicos en que se hace directa referencia a la historia reciente de Chile- el candidato de la derecha compara dos épocas del país. A sus ojos una es negativa, el pasado, y otra es positiva, el presente. Lavín no cita fechas precisas, pero es claro que la primera época remite a la guerra fría (décadas del 60, 70 y 80), mientras que la segunda se refiere a la transición democrática (década de los 90). En cada una de estas referencias no hay explicaciones históricas, así como tampoco se identifican responsables. El pasado es percibido como una época dominada por dos actores políticos mayores, Salvador Allende y Augusto Pinochet, quienes son asociados en un relato único a la idea de confrontación, de conflicto, de sufrimiento, sin hacer diferencias entre los regímenes democrático del primero y dictatorial del segundo.

En consecuencia, Lavín apela a una imagen del pasado en la que Allende y Pinochet son percibidos como los personajes principales de una época de la historia de Chile dominada por la guerra civil, imagen por lo demás que alude directamente a la doxa, como lo demuestran los estudios de opinión pública realizados en 1999 (Hunneus, 2001). De esta manera, y para que su tesis sea aceptada, el orador se apoya sobre un conjunto de lugares comunes pertenecientes a la doxa predominante (Amossy, 2006), donde el presente es, en cambio, percibido como una época ligada a la modernidad, a la tolerancia, a la reconciliación nacional y al crecimiento económico. El discurso del 10 de mayo, pronunciado ante los dirigentes de la CPC, muestra con extrema simplicidad la dicotomía entre pasado y presente:

Pero estoy feliz de que ya no vivamos en ese país del pasado en que todos estábamos divididos, en que nuestros proyectos de sociedad eran tan distintos. Nos acostumbramos a convivir juntos en casi diez años de democracia, resolviendo conflictos y problemas importantes (...) En los económico somos un país más moderno, integrado al mundo, con inflación baja, con consensos y acuerdos que para los chilenos de la década del 60 y 70 parecían un sueño irrealizable. (1999, p. 2)

En este extracto, Lavín utiliza dos argumentos que pertenecen a la familia argumentativa del cadrage: la disociación y la amplificación. El cadrage -o "encuadre"- es un tipo de argumento en el cual se insiste sobre ciertos aspectos favorables a la opinión y se disminuyen otros que podrían tener un efecto contrario (Breton, 2006). Así, la disociación 
de la noción "país" en "país del pasado" y "país del presente" permite presentarle al auditorio dos alternativas en las que se realzan y se disminuyen sus propiedades. Asimismo, la amplificación permite concentrar largamente la atención sobre ciertos elementos de una y otra alternativa, a través de la repetición, la acumulación de detalles y la división de un todo en varias partes (Breton, 2006).

Es necesario subrayar que la utilización de la tercera persona del plural -nosotrosfacilita a Lavín despojarse de su personaje de candidato político, sortear en el discurso su colaboración con el régimen militar y presentarse como un ciudadano ordinario. Como lo recuerda Charaudeau (2005), el político, en su singularidad, habla por todos en tanto portador de valores trascendentales; es la voz de todos a través de su voz. "Él establece un pacto entre tres tipos de voz: la de un ideal social, la del yo y la del tú-todos, todos los cuales se funden en un cuerpo social abstracto, a menudo expresado por un nosotros que juega el rol de guía" (Charaudeau, 2005, p. 61).

En otro discurso, el del 4 de noviembre, Lavín utiliza nuevamente la disociación de la noción "país", pero a partir de un tema específico, el de las elecciones presidenciales. Compara pasado y presente, aludiendo implícitamente a los últimos comicios electorales que precedieron a la caída del gobierno de Allende:

La gente está contenta de vivir en un país más democrático, más abierto, más tolerante. En un país más estable, en que a 38 días de una elección tan importante la vida sigue igual (...) El Chile del pasado, en que cada elección paralizaba al país y se ponían en juego modelos de sociedad tan diferentes, quedó definitivamente atrás. (1999, p. 1)

Cuando el candidato habla de "modelos de sociedad tan diferentes" se refiere muy probablemente a la diferencia entre los bloques socialista y capitalista de la guerra fría, es decir al contexto histórico en que se produjo la elección de Allende. Esta información está implícita, lo que permite reforzar la argumentación al presentar de manera velada e indirecta las creencias y opiniones del candidato. Ocurre muchas veces que en la argumentación, una idea formulada explícitamente por un argumentador tiende a ser rebatida por otro argumentador. En consecuencia, cuando se trata de una creencia fundamental, como una ideología por ejemplo, debe utilizarse un medio de expresión que no la haga rebatible, en este caso el implícito (Amossy, 2006).

Otro de los argumentos utilizados por Lavín en su campaña, y que pueden notarse en este extracto, es el argumento de comunidad. Breton (2006) señala que este tipo de argumento se apoya sobre supuestos comunes para mostrar que la opinión defendida es coherente con un valor o lugar común aceptado por el auditorio. Generalmente es reconocible por sus proverbios, fórmulas y máximas relacionadas con el saber popular, como en el extracto anterior: "la gente está contenta de vivir en un país más democrático, más abierto, más tolerante”. 
La idealización del presente es, entonces, el primer elemento que Lavín rescata desde la doxa para utilizarlo en su estrategia argumentativa. Desde la neutralidad de un ciudadano ordinario, sin militancia ni pasado políticamente comprometedor, el candidato de la derecha elimina de su discurso cualquier indicio que lo ligue a Pinochet o a su régimen.

Un segundo elemento de la doxa elegido por Lavín, para profundizar este alejamiento, es la sacralización del consenso entre la Concertación y la dictadura militar. Hermet (2001) recuerda que este compromiso, que implicaba la impunidad para los miembros de las Fuerzas Armadas acusados de violación a los Derechos Humanos, fue una fórmula que contribuyó a la estabilidad política de la transición democrática, "sin vencedores, ni vencidos". El consenso implica además erigir la reconciliación nacional en valor primordial de la nación, por sobre otros, como el de la justicia. Es en nombre de la reconciliación y de la estabilidad político-económica del país que es necesario olvidar el pasado y concentrarse en el presente, dejando a la justicia chilena operar independientemente. En un contexto de crisis de consenso, provocada por el arresto de Pinochet, los dirigentes políticos se asignan el rol de garantes de la unidad nacional, lo que significa que, en el tema de las violaciones a los Derechos Humanos, ellos adoptan la neutralidad, en nombre de la separación de los poderes del Estado -respeto a la independencia de los tribunales de justicia-.

Lo importante $-\mathrm{y}$ lo que se transforma en el punto de inflexión del discurso político de la derecha chilena- es que la detención del ex general y la reactivación de la cuestión de las violaciones a los Derechos Humanos permiten separar la imagen de Pinochet de la herencia político-económica de su régimen. La derecha está en condiciones, entonces, de defender esta herencia (incluso de justificar retrospectivamente la necesidad de un régimen autoritario) sin estar obligada a defender a la persona del detenido, lo que habría sido mucho más difícil si Pinochet hubiese estado en Chile durante la campaña presidencial (Joignant y Navia, 2003). La alocución del 4 de noviembre resume el sentido del discurso político de Lavín, concentrado en la promoción de la reconciliación por sobre el valor justicia:

Los chilenos quieren un gobierno que los acoja a todos. No quieren las divisiones: entre empresarios y trabajadores, entre poderosos y débiles, entre salud privada y pública, entre izquierda y derecha, entre civiles y militares. Quieren un país integrado. Un gobierno de paz. Sin exclusiones. (1999, p. 4)

El candidato de la derecha critica veladamente a la izquierda extraparlamentaria -más específicamente al Partido Comunista, principal promotor de un juicio a Pinochet en España- al hacer mención a las "divisiones entre empresarios y trabajadores, y poderosos y débiles”, es decir, al histórico discurso marxista que amplifica el conflicto de clases. La palabra "división" funciona aquí como un término reductor que asimila realidades muy 
complejas; todas las "divisiones" son puestas en un mismo plano y simplificadas al extremo, como cuando el candidato habla de la división entre izquierda y derecha y entre civiles y militares. A través de la amalgama, un tipo de argumento por asociación (perteneciente a la familia de argumentos de cadrage), Lavín simplifica y asimila dos divisiones complejas, que sobrepasan la sola disputa por el poder entre dos clivajes políticos o las tensiones entre gobierno y Fuerzas Armadas. Él subraya los aspectos más importantes del tema "divisiones entre los chilenos" y elige los que se ajustan a su argumentación, aquellos que forman parte de la doxa en tanto estereotipos o representaciones colectivas reconstruidas por el orador, en función de un modelo cultural preexistente.

La reconciliación es uno de los temas más importantes en el discurso político de Lavín, pues le permite evitar el asunto del juicio a Pinochet (en España o en Chile). Por lo mismo, él acude al argumento de autoridad, es decir a un personaje ajeno a la contingencia chilena, que pueda entregarle legitimidad a sus palabras y, por lo tanto, hacer más convincentes sus opiniones. En la misma alocución del 4 de noviembre, Lavín hace mención al Papa Juan Pablo II:

Cuando el Papa nos visitó hace doce años, nos dejó, entre muchos de sus testimonios, dos que quiero recordar aquí y que son para mí un mandato: dijo que los pobres no pueden esperar. Y dijo también que Chile tiene vocación de entendimiento. Esto será la esencia de mi gobierno. A ese proyecto los convoco a ustedes y a todos los chilenos. (1999, p. 5)

El candidato se apoya en la competencia moral del Papa y en su experiencia durante la resistencia de los polacos frente a los nazis y los comunistas, con el fin de hacer más aceptable y verosímil su opinión ("Chile tiene vocación de entendimiento"). En un argumento de autoridad, la razón de creer una conclusión no depende de su justeza, de su adecuación al mundo tal como es o debería ser, sino del hecho que dicha conclusión es apoyada por una persona que es garante de su justeza (Plantin, 1996).

Se puede decir entonces que, en esta estrategia de alejamiento respecto de Pinochet, la simplicidad y el re-encuadre de la realidad operan como ejes centrales. En este segundo eje, Lavín busca una serie de puntos de acuerdo entre el conjunto de representaciones socialmente predominantes, encontrando dos, que serán potenciados largamente durante la campaña: la idealización del presente, en detrimento de un pasado dominado por la desunión y la politización extrema, y la sacralización del consenso, donde la reconciliación es erigida en valor supremo por sobre la justicia. Ambos puntos de acuerdo le permiten al candidato evitar constantemente la imagen de Pinochet, así como cualquier discusión acerca de su colaboración con el régimen militar. Paralelamente a esta estrategia de alejamiento, Lavín defiende la institucionalidad política y económica heredada del régimen militar. 


\section{La defensa de la herencia político-económica del régimen militar}

Este término designa el conjunto de principios y valores impuestos a la sociedad chilena por la Fuerzas Armadas y la derecha durante el régimen militar, y que luego fueron adoptados por los partidos de centro izquierda. Yocelevzky (2002) señala que los siguientes principios y valores constituyen el fundamento de la transición democrática: la legitimidad del golpe de Estado de 1973 y de la Constitución de 1980, y la inmutabilidad del modelo económico impuesto por la dictadura. El discurso político de Lavín defiende esta herencia a través de dos ejes temáticos: la defensa de un Estado subsidiario y la crítica a los partidos y dirigentes políticos.

Millon-Delsol sostiene que:

La idea de subsidiariedad concierne el rol de la autoridad en general y no solamente aquella proveniente del Estado. Según esta idea, en la sociedad ninguna autoridad debe desbordar su esfera de competencias ( ... ) pues esta autoridad es inferior, no en valor sino en su superficie y poder. Una autoridad cualquiera debe ejercerse sólo para paliar la insuficiencia de una autoridad más pequeña. Si la insuficiencia de esta última es real, la primera tiene no sólo el derecho sino el deber de ejercerla. La subsidiariedad nos lleva a la noción de suplencia; la autoridad suple las deficiencias de un actor. (1992, p. 6)

A través de la idea de subsidiariedad, Lavín (y particularmente la UDI, cuya declaración de principios adopta esta idea como valor primordial) sacraliza al sector privado en detrimento del Estado, impedido de ejercer cualquier actividad que pueda ser realizada por el primero. Desde este punto de vista, el Estado está limitado, por una parte, a ejercer labores de administración en dominios estratégicos, tales como la defensa nacional, las relaciones internacionales y la justicia y, por otra parte, a resolver los problemas sociales, como la pobreza, cuya erradicación no depende del nivel de gasto social del gobierno sino más bien de la eficiencia con la cual se administra ese gasto; no importa la cantidad de recursos de que disponga el Estado, sino más bien la manera en que esos recursos son utilizados. El discurso del 10 de mayo refleja con claridad esta idea, que se repite en otras alocuciones del candidato:

El problema no son los recursos. El verdadero problema es que esos recursos no le llegan a la gente. De hecho el gasto social se ha duplicado en la última década como consecuencia de los mayores recursos que provienen del crecimiento económico. Sin embargo, las personas más pobres siguen levantándose igual a las 6 de la mañana para 
sacar número para que las atiendan en el consultorio y siguen mandando a sus hijos a escuelas que no les dan la calidad de educación adecuada. (1999, p. 9)

En la defensa de la herencia autoritaria, sobresale un segundo eje temático que corresponde a la crítica enconada a los partidos políticos y sus dirigentes, quienes estarían absorbidos por sus intereses corporativos e individuales así como por sus ideologías. El siguiente extracto del discurso del 10 de mayo ofrece un ejemplo de lo anterior:

Cuántas veces me ha tocado asistir a programas de televisión en que, cuando estoy hablando de las formas de enfrentar la delincuencia o la manera de eliminar las levantadas a las 6 de la mañana para sacar un número en un consultorio, viene alguien y pregunta: bien alcalde, pero volviendo ahora a los grandes temas nacionales ¿qué piensa usted de los senadores designados? ( ... Por dentro me dan ganas de decirle: ¿Cómo que los grandes temas nacionales? ¿Hasta cuándo caemos en la trampa de la política tradicional? Esa trampa tiende a asociar los grandes temas con los temas políticos. En cambio, las preocupaciones de la vida diaria de los chilenos serían una especie de tema menor. (1999, p.9)

En los cuatro discursos estudiados Lavín utiliza reiteradamente la frase "las preocupaciones de la vida diaria de los chilenos" o "los problemas reales de la gente" para referirse a las dificultades que sufren los chilenos durante la crisis económica asiática y conectarlas con la insatisfacción de la población frente a los partidos políticos. Las consecuencias de la crisis, como la cesantía y el aumento de la delincuencia, son percibidas en el discurso de Lavín como el resultado de "la política tradicional" de los gobiernos de la Concertación, cuya concentración estaría puesta en los partidos políticos y no en los problemas cotidianos de las personas. "La política tradicional" es, a los ojos del candidato de la derecha, una trampa montada por quienes privilegian las discusiones de orden político e histórico en detrimento de la resolución pragmática de los problemas de los chilenos. Él considera que los gobiernos no deberían estar ligados a la acción de los partidos ni al debate político pues ellos lentifican la toma de decisiones y la puesta en marcha de soluciones. El Estado es así percibido como una empresa que rinde servicios a la comunidad, de manera rápida y eficaz, sin detenerse en asuntos ideológicos o históricos.

Otra de las características de este extracto, y que se repite en otros discursos, es la imagen de outsider que Lavín desea mostrar. Él asegura que durante una entrevista fue interrumpido por preguntas sobre política tradicional, en momentos en que él hablaba sobre los problemas reales de la gente. De esta forma, él asocia "la trampa de la política tradicional" a los medios de comunicación, cuya agenda estaría dominada por una jerarquía de temas impuesta por el gobierno y los partidos políticos en general. Esta 
estrategia permite a Lavín sortear con éxito su identificación con un partido y reconstruir un ethos antaño relacionado con el régimen militar.

\section{Conclusión}

En los cuatro discursos estudiados, Joaquín Lavín utiliza de manera recurrente los argumentos de cadrage y de comunidad, tomando en cuenta la doxa existente en la época de la campaña presidencial. La realidad es así "encuadrada" y revestida de objetividad. Previo a la puesta en marcha de la estrategia argumentativa, el candidato liga los puntos de acuerdo de este auditorio con su propia opinión. La utilización de la doxa como plataforma de este tipo de argumentos demuestra la importancia asignada por el candidato de la derecha a los sondeos de opinión pública. Sus convicciones políticas ligadas a las de su partido, como por ejemplo la relevancia de Pinochet en la historia política de Chile- son reemplazadas permanentemente por las preferencias de la opinión pública. Así ocurre cuando él se desliga definitivamente de la imagen del ex dictador, poco después de su detención, acusando recibo de un juicio negativo de la población respecto de la figura del militar.

Por otra parte, el uso de argumentos de autoridad, menos constantes que los anteriores, explica la simplicidad del discurso político de Lavín. Recurrir a una autoridad externa, a una personalidad de renombre, al auditorio o a su propia experiencia en tanto alcalde exitoso, facilita su intento de convencer sin utilizar estructuras argumentativas demasiado complejas. Esta simplificación de los temas de la campaña presidencial y la construcción de un relato a través de implícitos son las características principales del discurso de Lavín, cuya estrategia descansa en la separación entre la imagen de un Pinochet sometido a juicio público y la herencia autoritaria de su régimen, así como en la crítica permanente a los partidos políticos.

La relación entre este discurso y los de la Concertación y de la izquierda extraparlamentaria será importante investigar a futuro: la sugerencia es que estos últimos pudieran haber replicado dichas características después de la elección de 1999 y que por lo tanto la reconstrucción del ethos discursivo transicional de los políticos chilenos tiene como fuente de inspiración el discurso político de Joaquín Lavín.

\section{Referencias bibliográficas}

Amossy, Ruth. (2006). L'argumentation dans le discours. París: Armand Colin. 
Breton, Philippe. (1999, marzo). La "préférence manipulatoire" du président du Front National. En Mots n58, pp. 101-125.

(2006). L'argumentation dans la communication. París: La Découverte.

Charaudeau, Patrick. (2005). Le discours politique. Les masques du pouvoir. París: Vuibert.

Gonzalez Camus, Ignacio. (2005). Joaquín Lavin, sonriendo por la vida. Santiago de Chile: Catalonia.

Hermet, Guy. (2001, septiembre). L'apurement du passé" Pouvoirs n98, pp. 89-101.

Hunneus, Cristián. (2000). El régimen de Pinochet. Santiago de Chile: Editorial Sudamericana.

------- (2001, julio). La derecha en el Chile después de Pinochet: el caso de la Unión Demócrata Independiente. Working Paper n²85. Obtenido el 22 de junio de 2007 en http://www.cerc.cl/Publicaciones/Derecha\%20en\%20Chile\%20despues\%20de\%20Pinochet, \%20caso\%20UDI.pdf.

Joignant, A. y Navia, P. (2003). De la política de individuos a los hombres de partido: socialización, competencia política y penetración electoral de la UDI (1989-2001), Estudios Públicos n89. Obtenido el 22 de junio de 2007 en: http://www.cepchile.cl/dms/lang_1/doc_3184.html

Maingueneau, D. y Charaudeau, P. (2002). Dictionnaire d'Analyse du discours. París: Seuil.

Millon-Del-Sol, Chantal. (1992). L'Etat subsidiaire. Ingérence et non-ingérence de l'Etat : le principe de subsidiarité aux fondements de l'histoire européenne, París: Presses Universitaires de France.

Ossa, Carlos. (2006, junio). La máquina de gastar. Ponencia presentada en Encuentro Internacional de Comunicación Comunicadores del siglo XXI: nuevos profesionales para nuevas audiencias. Obtenido el 6 de enero de 2009 en http://www.comunicacionmayor.cl/ponencias/Ponencia\%20CARLOS\%20OSSA.pdf.

Perelman, Chïm. (1977).L'empire rhétorique. París: Vrin.

Plantin, Christian. (1996). L'argumentation. París: Seuil.

Sarfati, Georges-Élia. (2005). Eléments d'analyse du discours. París: Armand Colin.

Yocelevzky, Ricardo. (2002). Chile, partidos politicos, democracia y dictadura, 1970-1990. Santiago de Chile: Fondo de Cultura Económica.

\section{Discursos:}

Anónimo (1999, mayo). Discurso de Joaquín Lavín en Seminario Icare. Obtenido en la Fundación Jaime Guzmán.

Anónimo (1999, junio). Discurso de Joaquín Lavín con motivo de la entrega de resultados del plebiscito nacional. Obtenido en la Fundación Jaime Guzmán.

Anónimo (1999, octubre). Discurso de Joaquín Lavín. Obtenido en la Fundación Jaime Guzmán.

Anónimo (1999, noviembre). Discurso de Joaquín Lavín en Calama. Obtenido en la Fundación Jaime Guzmán. 